\title{
Understanding Moral Injury Morbidity: A Qualitative Study Examining Chaplain's Perspectives
}

\author{
Rachel L. Boska ${ }^{1}$ D Shawn Dunlap ${ }^{2} \cdot$ Marek Kopacz $^{3} \cdot$ Todd M. Bishop $^{1,4}$. \\ J. Irene Harris ${ }^{5,6}$
}

Accepted: 25 August 2021 / Published online: 4 September 2021

This is a U.S. government work and not under copyright protection in the U.S.; foreign copyright protection may apply 2021

\begin{abstract}
Moral injury tends to be conceptualized through an interplay of psychological and religious concerns. Recent qualitative research has begun utilizing chaplains to bolster the understanding of moral injury within veterans. The current study examined qualitative data regarding how moral injury is viewed through the lens of Chaplain Services within the Veterans Health Administration (VA). Specifically, chaplains were asked to describe how moral injury presents, what kinds of complaints veterans voice with regard to moral injury, and how moral injury impacts social functioning. Chaplains highlighted how moral injury is a pervasive issue affecting veterans across multiple domains. Clinical implications discussed further.
\end{abstract}

Keywords Moral injury $\cdot$ Qualitative $\cdot$ Chaplain services $\cdot$ VA $\cdot$ Veterans

Rachel L. Boska

Rachel.Martin1@va.gov

1 VA Center of Excellence for Suicide Prevention, VA Finger Lakes Healthcare System, Canandaigua, NY 14424, USA

2 Center for Healthcare Organization and Implementation Research (CHOIR), VA Bedford Healthcare System, Bedford, MA 01730, USA

3 New Orleans, LA, USA

4 Department of Psychiatry, University of Rochester School of Medicine \& Dentistry, Rochester, NY 14642, USA

5 VISN 1 MIRECC, VA Bedford Healthcare System, Bedford, MA 01730, USA

6 University of Minnesota Medical School, Minneapolis, MN 55455, USA 


\section{Introduction}

Moral injury is a relatively new concept within the psychological literature (Litz et al. 2009; Shay 1995). Despite significant strides made in this field, much work remains to be done regarding the conceptualization, definition, and operationalization of the construct. The field's current understanding centers on the idea that moral injury encapsulates the complex interplay of emotional, psychological, spiritual, and/or social damage resulting from exposure to a situation that challenges the individual's deeply valued moral code (Litz et al. 2009). Moral injury itself is preceded by a potentially morally injurious event (PMIE), an event in which an individual either perpetuates, fails to prevent, bears witness to, or learns about actions that contradict their core moral beliefs (Litz et al. 2009). Betrayal from either leaders or peers has also been conceptualized as a PMIE that may result in moral injury (Shay, 1995). PMIEs are prevalent among combat veterans with estimates of 36.3-41.8\% reported experiencing at least one of these scenarios (Nichter et al. 2021; Wisco et al. 2017). Despite a sizeable percentage of combat veterans reporting at least one PMIE, there is no universally accepted definition of moral injury, making empirical investigation difficult (Kopacz et al. 2019).

One attempt at defining moral injury was Jinkerson's (2016) proposed diagnostic criteria; individuals who have moral injury must (a) have experienced an event that violates their moral beliefs, (b) have feelings of guilt, and additional symptoms that may indicate spiritual/existential conflict. Individuals' distress associated with moral injury tends to be conceptualized by researchers and clinicians through a religious or spiritual framework (Bryan et al. 2018; Currier et al. 2014; Fontana and Rosenheck 2004; Harris et al. 2008, 2012). Unlike PTSD, moral injury has been described as an "injury to the soul" rather than a fear-based disorder (Hodgson and Carey 2017, p. 1213). Furthermore, research has identified religious or spiritual struggles as common complaints of individuals with moral injury (Currier et al. 2019; Harris et al. 2015). Given the interplay between moral injury and religiosity, it has been recommended that treatment for moral injury incorporate religious and spiritual aspects into therapy (Currier et al. 2014).

Chaplain services play a crucial role in the identification and treatment of moral injury. In 2014, the US Department of Veterans Affairs (VA) initiated the Mental Health Integration for Chaplain Services to foster collaboration in therapeutic services between behavioral health clinicians and chaplains. Kopacz et al. (2018) found that a large majority of participants, who were VA staff members, identified moral injury as the domain of mental health providers (i.e., psychologists and social workers) and chaplains, further supporting the need to integrate both domains.

Recently, Koenig and Zaben (2021) reviewed the current evidence for moral injury treatments including those with a spiritual and pastoral care basis. The authors noted that

"Clergy with mental health training and chaplains are ideally positioned to address concerns about moral transgressions and help individuals to resolve symptoms of moral injury" (Koenig and Zaben 2021, p. 15). Initial examinations of spiritual and behavioral health treatment integration indicated positive effects (Antal 
et al. 2019; Cenkner et al. 2021). Most recently, a pilot study conducted an interdisciplinary moral injury group incorporating chaplain and behavioral health services to blend treatment and address the spiritual concerns within moral injury (Cenkner et al. 2021). Two additional randomized controlled trials support the efficacy of spiritually integrated care for moral injury (Harris et al. 2011, 2018). Results also support the utility of interventions that integrate behavioral health and chaplaincy. This suggests that given the religious or spiritual struggles associated with moral injury, future research should continue to foster interdisciplinary conceptualization and treatments for moral injury.

Given that moral injury is a relatively new construct and both researchers and clinicians continue to grapple with how to best define and treat it, there remains a need for more qualitative data to enhance our understanding of the morbidity associated with this debilitating syndrome (Frankfurt and Frazier 2016). Qualitative approaches have been demonstrated to be helpful when conceptualizing moral injury from providers (Drescher et al. 2011) and veterans (Vargas et al. 2013). More recent qualitative research has begun utilizing chaplains to bolster the understanding of moral injury within veterans (Drescher et al. 2018). Within their study, Drescher et al. (2018) identified specific events that chaplains identify as morally injurious, symptoms, and interventions, providing initial qualitative evidence to understanding moral injury through a chaplaincy lens. Continued research is necessary to understand how moral injury presents and the impact it has on veterans' functioning.

The current study sought to build upon Drescher et al.'s (2018) by gathering additional data regarding how moral injury is viewed through the lens of Chaplain Services within the VA. Specifically, chaplains were asked to describe how moral injury presents, what kinds of complaints veterans voice with regard to moral injury, and how moral injury impacts social functioning. Qualitative focus groups were conducted as part of a larger quality improvement effort aimed at standardizing spiritual assessment practices. The aim of the current project was to identify preliminary qualitative themes regarding the ways chaplains see moral injury present in their professional practice, including common symptoms and the impact that moral injury has on the lives of veterans.

\section{Methods}

\section{Participants}

The project was reviewed by the IRB and was deemed exempt from IRB review due to the minimal risk involved and deidentified interviews. Participants were VA chaplains; the Chief of Chaplains sent an e-mail invitation to all the chaplains at a large VA facility, inviting them to contact the research team if they would like to participate. The invitation made clear that the Chief would not know if any individual chaplains participated, so coercion would not be possible. Seven chaplains participated in two focus groups. The chaplains involved had a combined 39 years of experience working with veterans who manage moral injury syndrome. All chaplains had Masters of Divinity degrees, and 2 had Doctor of Ministry degrees. Three 
of the chaplains were also veterans and had experience addressing moral injury syndrome among active duty military personnel as well as veterans. The chaplains included three women and four men. Five identified as African-American and two identified as Caucasian. They each reported from 2 to 11 years of experience as a VA chaplain. Faiths represented included African Methodist Episcopal, American Baptist, Independent Evangelical, Pentecostal, Presbyterian, Southern Baptist, and United Church of Christ. The interviewer was a Caucasian psychologist/spiritual health researcher, experienced with qualitative focus group interviews, who identifies as a member of the United Church of Christ.

\section{Interview}

The qualitative interview requested the chaplains' perspectives on (a) how moral injury presents in chaplaincy settings, (b) how do veterans describe symptoms chaplains believe are related to moral injury, and (c) how moral injury impacts social functioning, community integration, and suicide risk. The questions were derived from the research team comprising senior-level chaplains and psychologists who had expertise in moral injury treatment and research. The goal of these questions was to understand the practical-level significance and impact of moral injury has on veterans. Each focus group was scheduled at mutual availability of the chaplains and interviewer. Both focus groups lasted approximately $90 \mathrm{~min}$. The focus groups were audio-recorded and then transcribed.

\section{Data Analysis}

A team of experienced qualitative researchers analyzed the data using the Hamilton Rapid Turnaround technique (Hamilton and Finley 2019), which collapses data into templates from which themes are drawn. As recommended for rapid turnaround techniques, the analytic team included individuals trained in diverse disciplines including anthropology, psychology, medicine, and chaplaincy (Beebe 2005). One anthropologist and one psychologist initially assembled a template table which was subsequently discussed, adapted, and themes ratified by team consensus. Results can be found in Table 1.

\section{Results}

\section{How Does Moral Injury Present in VA Chaplaincy Settings?}

In understanding moral injury, chaplains were first asked how they see moral injury present in veterans. Chaplains indicated that moral injury tends to present as "spiritual pain" and/or "crises of faith" and identified settings and periods of life in which moral injury may be prominent. One chaplain stated that moral injury presents during a life review or when the veteran "feels at ease." Similarly, another chaplain highlighted that moral injury is prominent when, "working with veterans at end of 


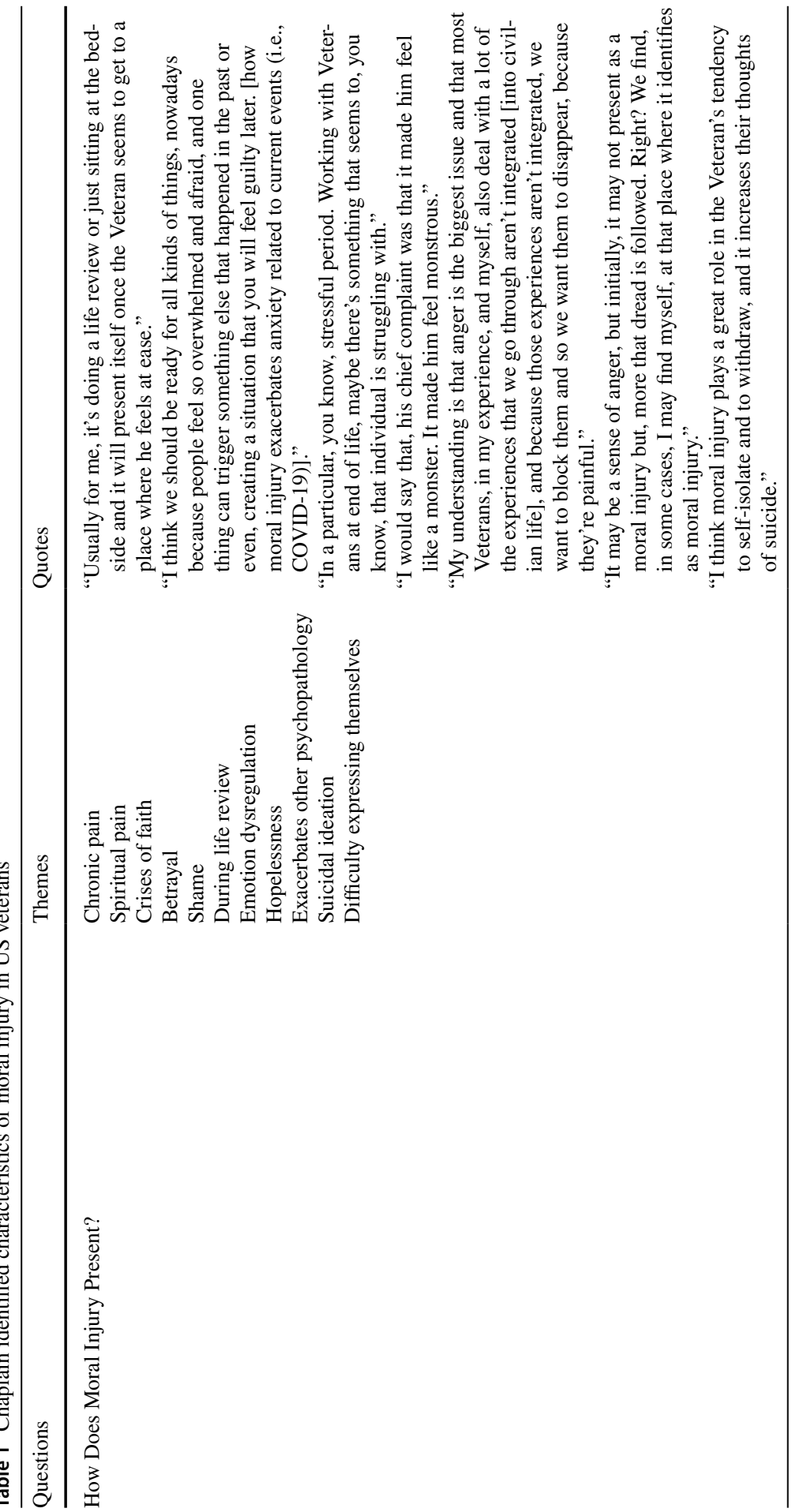




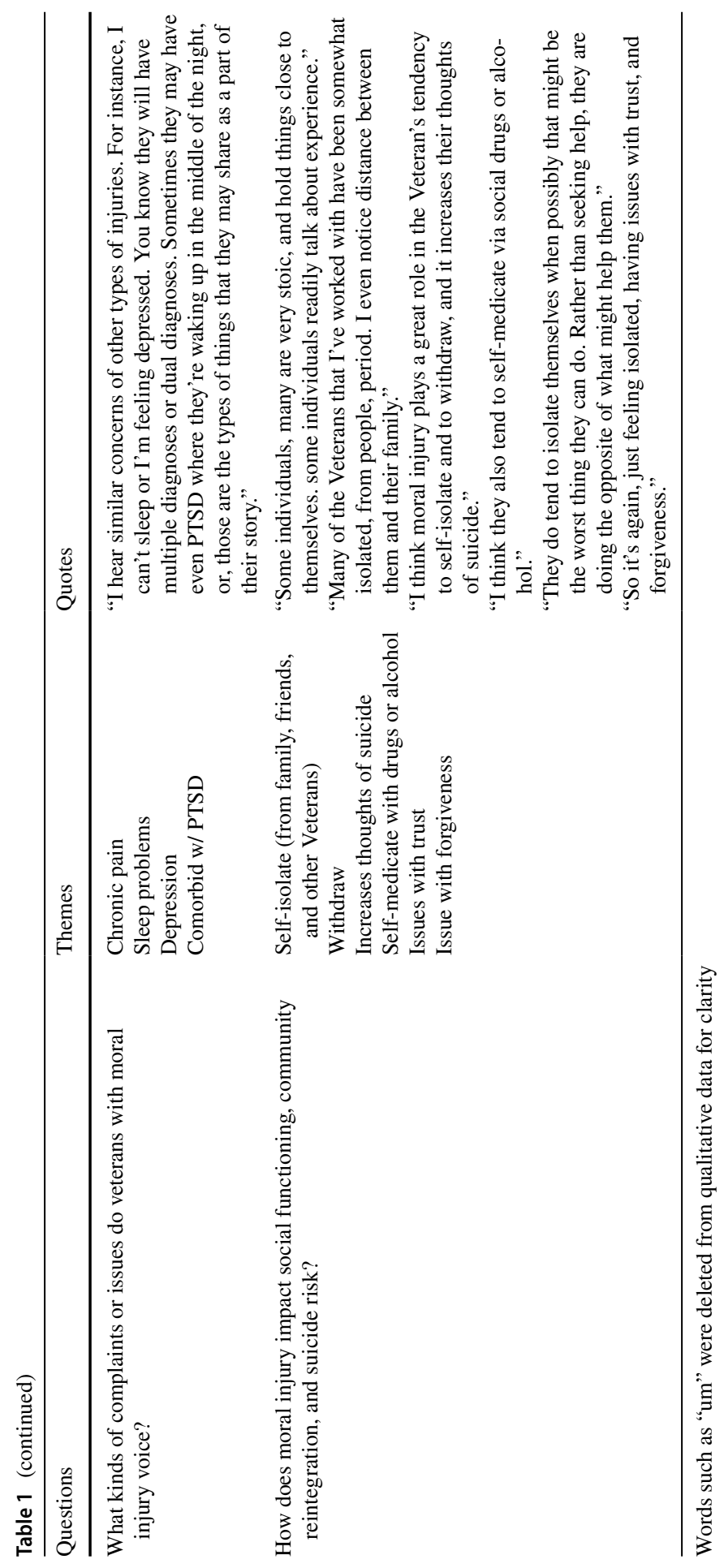


life, maybe there's something that seems to, you know, that the individual is struggling with."

Chaplains also emphasized that moral injury tends to exacerbate current psychopathology and may be a subliminal cause of distress potentially unknown to the veteran. Specifically, chaplains noted that individuals managing moral injury may isolate themselves and have difficulty expressing themselves emotionally. Anger tended to be a significant presentation noted among chaplains with multiple references toward anger and emotion dysregulation. Mirroring the hypothesized core components of moral injury, chaplains also identified betrayal and shame as two major presenting symptoms.

\section{What Kinds of Complaints or Issues Do Veterans with Moral Injury Voice?}

Chaplains were then asked to identify what complaints or issues do veterans with moral injury voice to chaplain services. Chaplains identified a wide range of symptoms they link to moral injury. Several chaplains noted a link between chronic pain and moral injury. As one chaplain surmised, "when a Veteran does not deal with their moral injury, that it will come out as chronic pain." Much like chronic pain, problems sleeping, the quality of sleep, and duration were also identified as major issues comorbid with moral injury. Chaplains in our focus groups also saw links with PTSD and the cascade of sleep issues associated with moral injury, "You know they will have multiple diagnoses or dual diagnoses. Sometimes they may have even PTSD where they're waking up in the middle of the night, or, those are the types of things that they may share as a part of their story."

Specific mental health issues such as depression were also cited as indicators signaling a need for a moral injury assessment. Depression, like sleep disorders, often leads to other issues which might prevent the successful treatment of the larger concerns such as moral injury and/or PTSD. Several chaplains saw depression as a gateway for including other mental health providers in the process of moral injury care saying, "I don't think it's an either/or. I think we both [chaplaincy and mental health] have to work together to help the Veteran heal from war injury or shame or depression... I think at that time, at that moment, I need to be letting my mental health colleague help me with that Veteran." PTSD was tightly linked with many issues that chaplains working with moral injury diagnosis attempt to identify and treat.

\section{How Does Moral Injury Impact Social Functioning, Community Integration, and Suicide Risk?}

The final question asked to chaplains was how moral injury affects veterans' functioning. Chaplains noted that many veterans who seek pastoral care for moral injury, "tend to self-medicate via social drugs or alcohol." Multiple chaplains identified moral injury impacting the social functioning of veterans through isolation and social withdrawal. The social separation often included the veterans' familial relationships, which was emphasized by one chaplain stating, "many of the Veterans 
that I've worked with have been somewhat isolated, from people, period. I even notice distance between them and their family." This maybe directly related to the difficulties with forgiveness and trust, which was also mentioned by chaplains.

Self-isolation and social withdrawal have been identified as warning signs for suicidal ideation (Lester et al. 2011). Within our focus groups, chaplains identified an association between suicide risk and moral injury via self-isolation and social withdrawal. Specifically, one chaplain stated, "I think moral injury plays a great role in the veteran's tendency to self-isolate and to withdraw, and it increases their thoughts of suicide." This, as another chaplain pointed out, "might be the worst thing they can do. Rather than seeking help, they are doing the opposite of what might help them."

\section{Discussion}

The current study sought to expand upon the literature by examining data identifying how moral injury is viewed through the lens of Chaplain Services within the VA. The results indicated some common themes among chaplains. Primarily, moral injury is a pervasive issue affecting veterans across multiple domains. Chaplains highlighted how moral injury can exacerbate other psychopathology including substance use disorder, anxiety, depression, and PTSD. Furthermore, chaplains indicated that moral injury affects veteran's interpersonal functioning. Previous literature has identified an association between moral injury and social disconnect (Martin et al. 2017; Vargas et al. 2013), which is a risk factor for suicidal ideation. Similarly, there has been empirical research identifying an association between moral injury and suicide (Ames et al. 2019; Bryan et al. 2018). However, it has been argued that moral injury and PTSD can occur independently of one another and do not share all the symptoms present in the DSM-5 entry for post-traumatic stress disorder (Bryan et al. 2018). The results of our focus groups seem to support this and suggest that these two diagnoses can be disentangled, allowing appropriate care practices to be utilized for a veterans specific mental and spiritual health needs.

This qualitative study adds to understandings of the morbidity associated with moral injury by drawing attention to some of the complaints voiced by veterans who present for VA chaplaincy services. We envision that drawing attention to these perspectives may lend itself to better supporting veterans impacted by moral injury. For example, clinical mental health care providers could use these findings to provide a more holistic measure of health care, specifically inclusive of any spiritual, religious, and/or faith-oriented concerns the veteran might be facing. Similarly, the chaplains who participated in this study readily acknowledged the value of and need for interdisciplinary collaboration. Besides pastoral care, these chaplains understood that veterans would oftentimes also need inherently clinical support for such mental health concerns as depression, PTSD, or suicidality.

There are notable limitations to this study. Although both genders were represented well in the focus groups, faiths represented were primarily conservative nonCatholic Christian denominations. These faith demographics are very representative of the VA facility in the Southeast from which the sample was drawn, but are not necessarily representative of faith demographics nationally. Further studies are 
recommended to assess if moral injury may be experienced or described differently among individuals with minority religious identifications or no religious identification; these findings should not be generalized to those populations. Furthermore, the use of rapid turnaround qualitative analysis was necessary to complete the larger project in which this study was embedded; further studies using depth analysis approaches may have the potential to draw a richer understanding of chaplains' perspectives on moral injury.

While these limitations are valid, it is still clear that chaplains' clinical observations are consistent with the empirical literature in that they observe associations with PTSD, depression, sleep disorders, and social withdrawal. The current investigation identified an association between moral injury and chronic pain, which should be subjected to future empirical investigation. Continued efforts to research and provide interdisciplinary care for moral injury are indicated.

Funding This study was funded by VA Rehabilitation Research \& Development, Award Number I21 RX003029-01A1.

Availability of Data and Material Inquiries and requests for data will be reviewed on a case-by-case basis. Inquires can be emailed to Dr. Harris at Jeanette.Harris2@va.gov.

Code Availability Not applicable.

\section{Declarations}

Conflict of interest The authors declare that they have no conflict of interest.

\section{References}

Ames, D., Erickson, Z., Youssef, N. A., Arnold, I., Adamson, C. S., Sones, A. C., Yin, J., Haynes, K., Volk, F., Teng, E. J., Oliver, J. P., \& Koenig, H. G. (2019). Moral injury, religiosity, and suicide risk in US veterans and active duty military with PTSD symptoms. Military Medicine, 184(3-4), e271-e278.

Antal, C. J., Yeomans, P. D., East, R., Hickey, D. W., Kalkstein, S., Brown, K. M., \& Kaminstein, D. S. (2019). Transforming veteran identity through community engagement: A chaplain-psychologist collaboration to address moral injury. Journal of Humanistic Psychology, 0022167819844071.

Beebe, J. (2005). Rapid assessment process. The encyclopedia of social measurement, 285-91.

Bryan, C. J., Bryan, A. O., Roberge, E., Leifker, F. R., \& Rozek, D. C. (2018). Moral injury, posttraumatic stress disorder, and suicidal behavior among National Guard personnel. Psychological Trauma: Theory, Research, Practice, and Policy, 10(1), 36.

Cenkner, D. P., Yeomans, P. D., Antal, C. J., \& Scott, J. C. (2021). A pilot study of a moral injury group intervention co-facilitated by a chaplain and psychologist. Journal of Traumatic Stress, 34(2), 367-374.

Currier, J. M., Holland, J. M., \& Drescher, K. D. (2014). Residential treatment for combat-related posttraumatic stress disorder: Identifying trajectories of change and predictors of treatment response. PLOS ONE, 9(7), e101741.

Drescher, K. D., Currier, J. M., Nieuwsma, J. A., McCormick, W., Carroll, T. D., Sims, B. M., \& Cauterucio, C. (2018). A qualitative examination of VA chaplains' understandings and interventions related to moral injury in military veterans. Journal of Religion and Health, 57(6), 2444-2460. 
Drescher, K. D., Foy, D. W., Kelly, C., Leshner, A., Schutz, K., \& Litz, B. (2011). An exploration of the viability and usefulness of the construct of moral injury in war veterans. Traumatology, 17(1), 8-13.

Fontana, A., \& Rosenheck, R. (2004). Trauma, change in strength of religious faith, and mental health service use among veterans treated for PTSD. The Journal of Nervous and Mental Disease, 192(9), 579-584.

Frankfurt, S., \& Frazier, P. (2016). A review of research on moral injury in combat veterans. Military Psychology, 28(5), 318-330.

Hamilton, A. B., \& Finley, E. P. (2019). Qualitative methods in implementation research: An introduction. Psychiatry Research, 280, 112516.

Harris, J. I., Erbes, C. R., Engdahl, B. E., Ogden, H., Olson, R. H., Winskowski, A. M. M., Campion, K., \& Mataas, S. (2012). Religious distress and coping with stressful life events: A longitudinal study. Journal of Clinical Psychology, 68(12), 1276-1286.

Harris, J. I., Erbes, C. R., Engdahl, B. E., Olson, R. H., Winskowski, A. M., \& McMahill, J. (2008). Christian religious functioning and trauma outcomes. Journal of Clinical Psychology, 64(1), 17-29.

Harris, J. I., Erbes, C. R., Engdahl, B. E., Thuras, P., Murray-Swank, N., Grace, D., Ogden, H., Olson, R. H. A., Winskowski, A. M., Bacon, R., Malec, C., Campion, K., \& Le, T. (2011). The effectiveness of a trauma focused spiritually integrated intervention for veterans exposed to trauma. Journal of Clinical Psychology, 67(4), 425-438.

Harris, J. I., Usset, T., Voecks, C., Thuras, P., Currier, J., \& Erbes, C. (2018). Spiritually integrated care for PTSD: A randomized controlled trial of "Building Spiritual Strength.” Psychiatry Research, 267, 420-428.

Hodgson, T. J., \& Carey, L. B. (2017). Moral injury and definitional clarity: Betrayal, spirituality and the role of chaplains. Journal of Religion and Health, 56(4), 1212-1228.

Jinkerson, J. D. (2016). Defining and assessing moral injury: A syndrome perspective. Traumatology, $22(2), 122$.

Koenig, H. G., \& Zaben, F. A. (2021). Moral injury: An increasingly recognized and widespread syndrome. Journal of Religion and Health. https://doi.org/10.1007/s10943-021-01328-0

Kopacz, M. S., Adams, M. S., Searle, R., Koenig, H. G., \& Bryan, C. J. (2019). A preliminary study examining the prevalence and perceived intensity of morally injurious events in a veterans affairs chaplaincy spiritual injury support group. Journal of Health Care Chaplaincy, 25(2), 76-88. https:// doi.org/10.1080/08854726.2018.1538655

Kopacz, M. S., Charpeid, G. L., Hollenbeck, L. A., \& Lockman, J. (2018). Examining moral injury awareness in a clinical setting. Journal of Military and Veterans' Health, 26(1), 11-14.

Lester, D., McSwain, S., \& Gunn, J. F. I. I. I. (2011). A test of the validity of the is path warm warning signs for suicide. Psychological Reports, 108(2), 402-404. https://doi.org/10.2466/09.12.13.PR0. 108.2.402-404

Litz, B. T., Stein, N., Delaney, E., Lebowitz, L., Nash, W. P., Silva, C., \& Maguen, S. (2009). Moral injury and moral repair in war veterans: A preliminary model and intervention strategy. Clinical Psychology Review, 29(8), 695-706.

Martin, R. L., Houtsma, C., Bryan, A. O., Bryan, C. J., Green, B. A., \& Anestis, M. D. (2017). The impact of aggression in the relationship between betrayal and belongingness among U.S. military personnel. Military Psychology, 29, 271-282. https://doi.org/10.1037/mil0000160

Nichter, B., Norman, S. B., Maguen, S., \& Pietrzak, R. H. (2021). Moral injury and suicidal behavior among US combat veterans: Results from the 2019-2020 National Health and Resilience in Veterans Study. Depression and Anxiety, 38(6), 606-614.

Shay, J. (1995). Achilles in Vietnam: Combat trauma and the undoing of character. Atheneum.

Vargas, A. F., Hanson, T., Kraus, D., Drescher, K., \& Foy, D. (2013). Moral injury themes in combat veterans' narrative responses from the National Vietnam Veterans' Readjustment Study. Traumatology, 19, 243-250.

Wisco, B. E., Marx, B. P., May, C. L., Martini, B., Krystal, J. H., Southwick, S. M., \& Pietrzak, R. H. (2017). Moral injury in US combat veterans: Results from the national health and resilience in veteran depression study. Depression and Anxiety, 34(4), 340-347.

Publisher's Note Springer Nature remains neutral with regard to jurisdictional claims in published maps and institutional affiliations. 